\title{
Chocolate, Fashion, Toys and Cabs: The Misunderstood Distinctiveness of Non-Traditional Trademarks
}

\author{
Irene Calboli
}

Published online: 8 January 2018

(C) Max Planck Institute for Innovation and Competition, Munich 2018

What do Cadbury, Toblerone and Kit-Kat chocolates, the Rubik's Cube and Lego mini-figurine toys, Louboutin shoes, Bottega Veneta bags and London Taxi Company cabs all have in common? These products have been, along with several others, protagonists of the rising trend of registering shapes and other nontraditional trademarks in a variety of countries, and then, in several cases, protagonist of ensuing litigation addressing the validity of these marks. To a large extent, the review panels and the courts involved in these cases have declared several of these marks invalid or have reduced their scope considerably. Hence, these cases have often involved several degrees of litigation and have been heralded in the news. In some instances, the courts have also upheld the validity of nontraditional marks and the possibility to register these signs, for example, with respect to the registrability of the décor of the Apple Store.

It is no secret that the domain of trademark law and the scope of trademark protection has grown exponentially in the past decades. Today, any sign can be registered as a mark. This includes single colors, shapes, sounds, smells, video clips, holograms and even gestures. The very broad definition of trademarks in the 1994 Agreement on Trade-Related Aspects of Intellectual Property Rights (TRIPS) confirmed the possibility to protect all these types of marks, commonly referred to as non-conventional or non-traditional marks, on a worldwide scale. Moreover, TRIPS only permits, but does not mandate, that members provide that signs should be "visually perceptible" to be protected as marks. The adoption of the Trademark Law Treaty and the Singapore Treaty on the Law of Trademarks in the following years further facilitated the registrability of these signs. Recent bilateral and

\footnotetext{
I. Calboli $(\bowtie)$

Texas A\&M University School of Law, Fort Worth, USA

e-mail: icalboli@law.tamu.edu

I. Calboli

School of Law, Singapore Management University, Singapore, Singapore
} 
plurilateral international trade agreements have continued on the same path. As a result, a wide variety of non-traditional marks have been registered in many countries and in the European Union. A search through national registries reveals a long list of these marks, particularly shapes and colors, including combinations of or even single colors.

However, this expansion of the scope of trademark protection has been accompanied only by a partial expansion of the grounds for denying these registrations or the creation of defenses to permit relevant uses of these or similar signs in the interest of competition or other non-commercial uses. For example, TRIPS only allows, but again does not mandate, that members adopt limitations and exceptions to trademark rights. Hence, the expansion of protection to non-traditional marks can have serious effects on market competition as these signs often protect products or parts of products, per se. Likewise, the protection of these signs can prevent other socially valuable uses of these or similar signs in related or unrelated non-commercial contexts. The potential harm that the protection of these signs can entail for market competition as well as cultural and artistic freedom is even more dramatic when one considers that the protection granted to trademarks may last in perpetuity. For the signs that acquire the status of well-known or famous marks, or simply for marks that have a reputation (in the EU and countries that use a similar wording in their laws), this protection additionally extends to non-similar goods and services.

Several courts across the world seem to share these concerns. As mentioned above, several courts have invalidated some prominent non-traditional marks in recent years. Hence, as lawyers and academics know too well, the cases that are litigated are just a small fraction of the claims that are brought (at times arbitrarily) by trademark owners. Most of these claims settle in secret, and often involve licensing or co-existence agreements, or simply the acceptance by third parties not to use the non-traditional mark in the future. Only defendants with "deep pockets" can afford expensive and lengthy litigation (such as Yves Saint Laurent, Cadbury, Nestle, etc.), thus the potential chilling effects of protecting non-traditional marks on both market competition and freedom of expression are difficult to quantify in practice. Even though prominent marks have been cancelled, many are still registered and only a handful of applications seem to get the necessary extra scrutiny that may be required by the trademark examiners or the review panels in charge of oppositions or cancellations before the registration of these marks.

\section{How Did We Get Here?}

The reason for the rise of non-traditional trademarks lies at the heart of the requirement for trademark protection - the notion of distinctiveness. In particular, rather than continuing to represent a requirement necessary for a mark to identify goods or services in the marketplace, distinctiveness has come to mean little more than "recognizable" by the human senses when it is applied by trademark examiners to the distinctive features of the signs that are applied to be protected as marks. In particular, signs only need to be "capable of distinguishing" commercial 
source under most legal definitions today. Also in countries, such as the United States, that require secondary meaning to register some of these signs, the bar to prove distinctiveness is very low. In other words, the current system has become circular, so that any distinctive sign, including products or product features, can be potentially protected as a mark. This includes the shape of Kit-Kat or Toblerone chocolates, the shape of Lego figurines, the Rubik's Cube, the sole of Louboutin shoes, the shape of Bottega Veneta bags and of the London taxi cabs - which are all very distinctive design features of the products (if not the overall products), but which were certainly never meant to be marks in the traditional sense, but rather constitute designs or creative works and as such deserve protection as designs or copyrights.

This circularity between the notion of distinctiveness and trademark-protectable subject matter is coupled with a weak system both in terms of absolute grounds to refuse trademark registration as well as trademark defenses across many jurisdictions. For example, historically, shape marks could not be registered at all in several countries, including the United Kingdom and Germany. These prohibitions are long gone and have been replaced, in several countries, with a list of absolute grounds that prevent trademark registration. These include exclusion from registration of signs that are "functional" in the U.S. Lanham Act and "aesthetically functional" under U.S. case law, or signs that comprise of the "shape, or another characteristic" of a product that either "results from the nature of the goods" or "is necessary to obtain a technical result" or "gives substantial value to the goods" in the EU. In fairness, courts have increasingly resorted to these provisions to deny protection to non-traditional trademarks. Hence, again, these cases are only the tip of the iceberg of potentially many more cases that are settled. Moreover, no sound defenses have been crafted, to date, to limit the use, and potential abuses, of nontraditional trademarks. For example, the defense based on the right to use a mark descriptively remains hard to invoke in these contexts, and the judicial doctrine of aesthetic functionality remains primarily a U.S.-based doctrine and has been applied inconsistently to date.

\section{What Could Be Done?}

In concluding, I would like to suggest that more attention has to be paid to the process of registration of non-traditional trademarks, particularly for the signs that could also be protected (or are protected) as industrial designs or design patents. As I have mentioned, the current definition of trademarks has led to a slippery slope situation where anything that is capable of distinguishing, because it is either original or interesting to the eye (and well-advertised), can be registered as a mark. Accordingly, trademark examiners should require a higher degree of secondary meaning before registering these marks. They should also strictly enforce the existing absolute grounds and scrutinize further whether these signs may fall under these prohibitions. During the recent wave of litigation, it has become apparent that several signs that were opposed and contested at the time of application were still registered by trademark offices, only to be denied protection later when the judiciary 
intervened in these disputes. Trademark examiners and trademark offices should (and probably already do) take these decisions as new guidelines to enforce stricter standards when examining the applications to register non-traditional marks.

Moreover, the courts could go further and use the actual drawings in every trademark registration, as it has been registered, to define the scope of trademark infringement, particularly the similarity of the registered marks and potentially infringing signs. For example, the Lego mini-figurine is registered as a simple shape figurine, without any ornaments, hair or hats. Should competitors make a specific type of figurine that is similar to the Lego figurines, but a character that is different from any existing Lego figurine, courts should rely on the Lego figurine mark, as registered, in the instance of a claim of infringement, to assess similarity and in turn a likelihood of confusion. In addition, the courts should continue to enforce the existing limitations and declare the registration of these marks invalid anytime these registrations should not have been granted due to the existence of an absolute ground for refusal of registration. In particular, courts should scrutinize strictly whether these marks are shapes and other characteristics that give value to the goods per se and cancel the marks when these conditions arise. This may often be the case, as these marks frequently do give value to the goods beyond their trademark distinctive function, as these marks often are the goods, or parts of them.

Ultimately, the proliferation of non-traditional trademark registrations, applications, and the recent wave of litigation in this area, is symptomatic of the larger disease of "intellectual property protection grabbing". Non-traditional trademarks protect products and features that, as I have mentioned, usually constitute product design or could perhaps be protected under copyright. Not surprisingly, some of the most heralded lawsuits in the area involve companies trying to prolong their exclusive rights in a valuable product through trademark protection, as trademarks grant a low-cost, low-barrier entry to protection with potentially high rewards. Yet, should this situation be allowed to continue? As increasingly noted by the courts, this trend can lead to abuses. Trademark rights are supposed to be granted to signs that are needed to distinguish products in the marketplace, not to every possibly distinctive sign. Thus, no matter the pressure from trademark owners and their lawyers, trademark examiners, trademark offices and the courts should (continue to) restore appropriate limitations to the registration and enforcement of these marks. This is crucial to safeguard market competition and freedom of culture and expression, and ultimately to prevent more abuses to the trademark system. 